\title{
ARTHROSCOPY OF THE KNEE; \\ IMPACT OF INTRAARTICULAR PAIN MANAGEMENT \\ fauziamoghees@gmail.com
}

FRCS (I), FRCS (Ed.)

Associate Professor,

Consultant Orthopedic Surgeon

KRL Hospital, Islamabad

Correspondence Address: Dr. Moghees Ikram Ameen 243A, Street No. 15, Race Course Grds

Rawalpindi

fauziamoghees@gmail.com

Article received on: 19/09/2016

Accepted for publication: 15/11/2016

Received after proof reading: 00/00/2016

\section{Dr. Moghees Ikram Ameen}

ABSTRACT... Introduction: Arthroscopy has a significant efficacy amongst patients, but is dependent on the anasthesia used. This is particularly important, as research on knee arthroscopy has established importance on anasthesia, particularly the type and number used. Study Research Objective: This study conducted over a period of 2 years, included all patients undergoing knee arthroscopy, irrespective of age, gender and underlying conditions (whether traumatic, degenerative, infective or inflammatory). In this study the Impact of postoperative pain management on patient recovery was evaluated. There is evidence that the knee joint has morphine receptors, thus nalbuphin was used. Study Design: Randomized Case Control Study. Setting: Department of KRL Hospital. Period: Jan 2014 to Dec 2015. Methodology: Randomization was done through the random number generator function provided by Open EPI Ver. 3.01. The random numbers generated were compared with serial numbers assigned to patients through consent forms and then assigned to the three groups accordingly (Control, Lignocaine, Lignocaine + Nalbucin). Out of 117 patients 6 patients were given general anesthesia and 111 were given spinal anesthesia. Arthroscopy was done under tourniquet control. To measure pain thresholds, a visual analogue scale from 1 to 9 was used and then made into three groups: mild (1-3), moderate (4-6) and severe (7-9). Patient Mobilization was measured 4, 6, 8, 10, 12, 14, and 16 hours post operation. Analysis was done using OpenEPI Ver. 3.01 and Microsoft Excel 2013 separately for both Lignocaine and Lignocaine + Nalbuphin. A systematic literature review was done to compare the results found in this study with those found in this study. For this purpose, the following string was used in Google Scholar and Pubmed: "Arthroscopy" AND "TB" AND "Synovial Biopsy" and "Postoperative Pain Management" AND "Arthroscopy" AND "Knee Joint". Results: Interventions of Lignocaine and Lignocaine + Nalbucin were more effective than control. Lignocaine + Nalbucin combined showed higher chances of mobility when compared to Lignocaine and control. Systematic Literature Review also provided similar results. Conclusion: If this procedure is performed with the correct expertise and the patient given intra articular lignocaine and Nalbuphin, the patients show early and good recovery and therefore they can be discharged the same day thus reducing the cost on the patient as well as the hospital.

Key words: Knee Arthroscopy, Lignocaine, Randomized Case Control Study, PostOperative Pain Management on Patient Recovery.

Article Citation: Ameen MI. Arthroscopy of the knee; impact of intraarticular pain management. Professional Med J 2016;23(12):000-000. Professional Med J 2016;23(12):1587-1592. DOI: 10.17957/TPMJ/16.3636

\section{INTRODUCTION AND RESEARCH OBJECTIVE} Arthroscopy in our setting and in our patients still is attributed to a major surgical procedure and therefore carries with it apprehension of pain and limitation of movement. ${ }^{1-3}$ This study conducted over a period of 2 years, included all patients undergoing knee arthroscopy, irrespective of age, gender and underlying conditions (whether traumatic, degenerative, infective or inflammatory). Patients with Septic Arthritis were not included. In this study the impact of post- operative pain management on patient recovery was evaluated. There is evidence that the knee joint has morphine receptors (Alagol et al. 2005 Al Otaibi. 2013). Since Morphine is not easily available a synthetic analogue Nalbuphin has been used instead.

\section{METHODOLOGY \\ Study \\ Study design was first accepted by Ethical Department of KRL Hospital. The study}


duration was from Jan 2014 to Dec 2015. This study included all patients undergoing knee arthroscopy, irrespective of age, gender and underlying conditions (whether traumatic, degenerative, infective or inflammatory). The patients were informed of the study and provided a consent form regarding the research objective, location of study, and duration of study. Out of 207 patients, 117 participated for the whole duration of the study.

Randomization was done through the random number generator function provided by OpenEPI Ver. 3.01. The random numbers generated were compared with serial numbers assigned to patients through consent forms and then assigned to the three groups accordingly. Group I composed of patients who were not given any intra articular drug for pain management prior to completion of the procedure; Group II composed of patients who were given $3 \mathrm{ml}$ of $2 \%$ Lignocaine intraarticular for pain management prior to completion of the procedure; Group III composed of patient who were given $3 \mathrm{ml}$ of $2 \%$ lignocaine plus 10mg of Nalbuphin intraarticular for pain management prior to completion of the procedure. Out of 117 patients 6 patients were given general anesthesia and 111 were given spinal anesthesia. Arthroscopy was done under tourniquet control. To measure pain thresholds, a visual analogue scale from 1 to 9 was used and then made into three groups: mild (1-3), moderate (4-6) and severe (7-9). Patient Mobilization was measured $4,6,8,10,12,14$, and 16 hours post operation. The findings of the study were independent of gender, age, and operation procedure used.

Analysis was done using OpenEPI Ver. 3.01 and Microsoft Excel 2013 separately for both Lignocaine and Lignocaine + Nalbuphin. The three tier exposure was done independent of gender and age to first compare standard treatment with new treatment (here being Lignocaine + Nalbuphin). In order to determine goodness of fit of data (and therefore, the acceptability of findings), a chi-square and power of outcome test were first undertaken to compare results.

\section{Systematic Literature Review}

A systematic literature review was done to compare the results found in this study with those found in other studies. For this purpose, the following string was used in Google Scholar and Pubmed:

- "Postoperative Pain Management" AND "Arthroscopy" AND "Knee Joint"

In Pubmed, article searching strings had used $\mathrm{MeSH}$ terms, which are as follows

- (("Pain, Postoperative/classification"[Mesh]) AND "Arthroscopy"[Mesh]) AND "Knee Joint"[Mesh]

Selection Criteria for articles consisted of: articles which contained all of the key words; were published between 2000 and 2015; contained high level of evidence, i.e. randomized control trail and case control studies were only included; showed a comparison between at least two different analgesics, method having no relevance to the research objective of this study; concerned with those patients aged 10 and above (preadolescents were not considered in this study).

\section{RESULTS}

Figure 1 provides an age distribution of the patients who took part in this study (Mean $=42$, S.D. $=44) .87 .2 \%$ of patients were distributed between the ages 21 and 60. Furthermore, the modal groups for age distribution are 21 to 30,31 to 40 , and 51 to 60 .

\section{Patient Age Distribution}

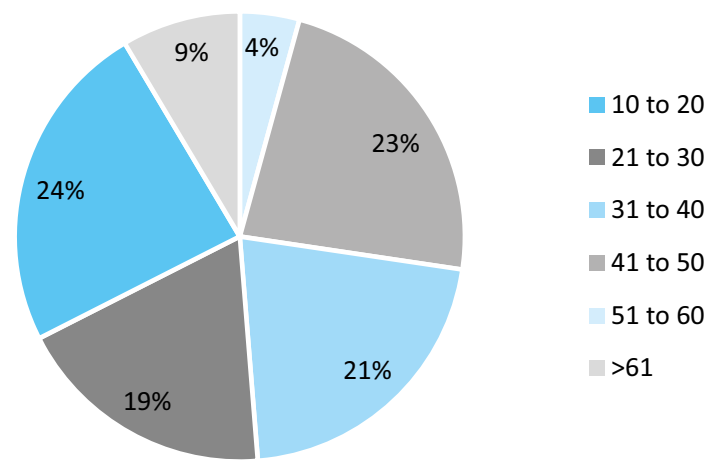

Figure-1. Age Distribution in Study 
Of 117 patients, 75 were men and 42 were female. The intervention found that there were $28 \%$ more men who had participated in this study.

\section{Gender Distribution}

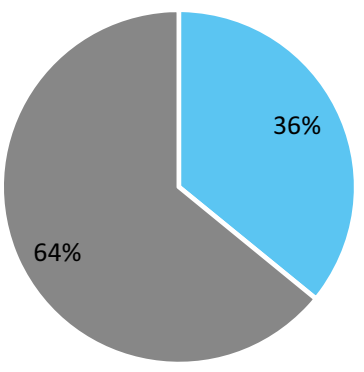

Women

- Men

Figure-2. Gender Distribution of Study chance of mild pain than Lignocaine. This is further shown by a higher Odds of Expectation of Mild Pain Threshold in the case of Lignocaine + Nalbuphin, which is 4.5 higher than that of Lignocaine.

Pain Threshhold distribution by Analgesic

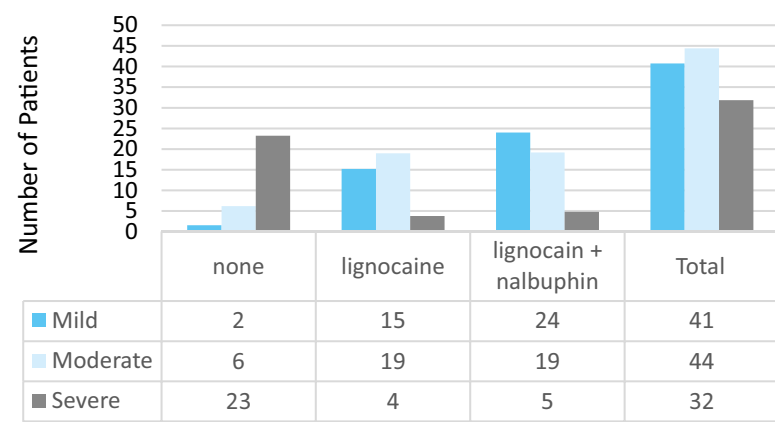

Figure-3. Pain Threshold distribution by Analgesic

Figure 4 provides data on distribution of patients based on mobility after treatment. $20.5 \%$ of patients who had been treated with combined Lignocaine and Nalbuphin showed mobility 4 hours after treatment. Furthermore, the intervention indicated a $4.3 \%(95 \% \mathrm{Cl} 4.085$ - 4.515) difference between Lignocaine and combined Lignocaine and Nalbuphin. for Lignocaine + Nalbuphin has a 0.16 greater

\begin{tabular}{|c|c|c|c|c|c|}
\hline \multicolumn{6}{|c|}{ Stratum 1 (Lignocaine only) } \\
\hline Pain Threshold & Cases & Controls & Total & Odds of Exp. & Odds Ratio \\
\hline Mild & 15 & 2 & 17 & 7.5 & 1 \\
\hline Moderate & 19 & 6 & 25 & 3.17 & 0.42 \\
\hline Severe & 4 & 23 & 27 & 0.17 & 0.02 \\
\hline Total & 38 & 31 & 69 & & \\
\hline \multicolumn{6}{|c|}{ Stratum 2 (Lignocaine + Nalbuphin) } \\
\hline Pain Threshold & Cases & Controls & Total & Odds of Exp. & Odds Ratio \\
\hline Mild & 24 & 2 & 26 & 12 & 1 \\
\hline Moderate & 19 & 6 & 25 & 3.17 & 0.26 \\
\hline Severe & 5 & 23 & 28 & 0.22 & 0.02 \\
\hline Total & 48 & 31 & 79 & & \\
\hline \multicolumn{6}{|c|}{ Mantel-Hänszel Summary Odds Ratios and Crude OR for Each Exposure Level } \\
\hline Exposure & & \multicolumn{2}{|c|}{ MH Summary OR } & \multicolumn{2}{|c|}{ Crude OR } \\
\hline Level 0 vs. Level 0: & & & 1 & 1 & \\
\hline Level 1 vs. Level 0: & & & 0.332 & 0.325 & \\
\hline Level 2 vs. Level 0: & & & 0.02 & 0.02 & \\
\hline
\end{tabular}

Table-I. Odd Ratios for both Lignocaine and Lignocaine + Nalbuphin 
Duration of Stay till Mobilization

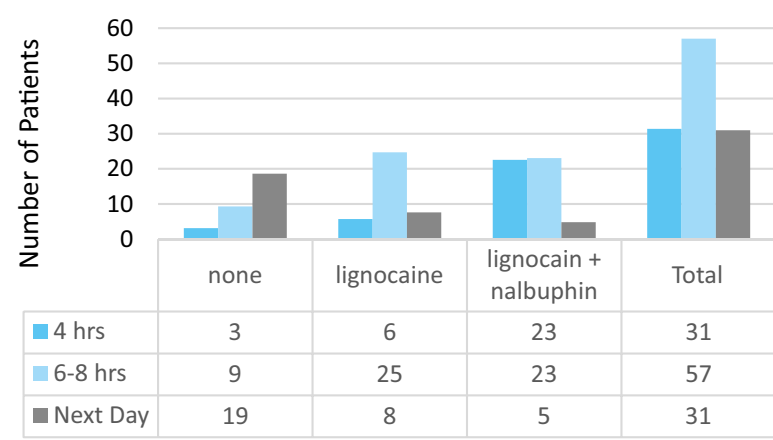

Figure-4. Duration of Stay till Mobilization

Combined Lignocaine and Nalbuphin also had an $8.8 \%(95 \% \mathrm{Cl} 8.36-9.24)$ difference when compared with Lignocaine. It is also pertinent to mention that only $2.1 \%$ of patients treated with combined Lignocaine and Nalbuphin were mobilized the next day, which is $13.8 \%$ lower than control.

Response time analysis is provided in Table II. OR with Lignocaine shows that combined Lignocaine + Nalbuphin treatment has a 0.10 lower OR than Lignocaine for mobilization of patients on the next day, and 0.22 lower OR for mobilization within 6-8 hours.

\section{SENSITIVITY ANALYSIS}

The table below provides an analysis of power of this study when taking interventions into consideration. This sensitivity analysis indicates that the Odds Ratio of the intervention has a higher likelihood of succeeding when compared to no intervention.

\begin{tabular}{|l|c|}
\hline \multicolumn{2}{|c|}{ Power for Unmatched Case-Control Studies } \\
\hline & Input Data \\
\hline Two-sided confidence interval (\%) & 95 \\
\hline Number of cases & 86 \\
\hline Percent of exposure among cases (\%) & 73.5 \\
\hline Number of controls & 31 \\
\hline Percent of exposure among controls (\%) & 26.5 \\
\hline Odds Ratio & 7.7 \\
\hline & \\
\hline Power based on: & \\
\hline $\begin{array}{l}\text { Normal approximation } \\
\text { Normal approximation with continuity } \\
\text { correction }\end{array}$ & $99.82 \%$ \\
\hline
\end{tabular}

Table-III is results of $t$-test done comparing both interventions (Lignocaine and Lignocaine + Nalbuphin) with no intervention. The positive value for $\mathrm{t}$-test shows that the null hypothesis (here being that no intervention has a higher significance than any intervention) can be rejected.

\section{SYSTEMATIC LITERATURE REVIEW Postoperative Pain Management in Arthroscopy of Knee Joint}

Screening was done from 19 articles which had fulfilled the selection criteria.

\begin{tabular}{|c|c|c|c|c|c|}
\hline \multicolumn{6}{|c|}{ Stratum 1 (Lignocaine) } \\
\hline Mobility & Cases & Controls & Total & Odds of Exp. & Odds Ratio \\
\hline $4 \mathrm{hrs}$ & 11 & 3 & 14 & 3.67 & 1 \\
\hline $6-8 \mathrm{hrs}$ & 19 & 9 & 28 & 2.11 & 0.58 \\
\hline Next Day & 8 & 19 & 27 & 0.42 & 0.11 \\
\hline Total & 38 & 31 & 69 & & \\
\hline \multicolumn{6}{|c|}{ Stratum 2 (Lignocaine + Nalbuphin) } \\
\hline $4 \mathrm{hrs}$ & 22 & 3 & 25 & 7.33 & 1 \\
\hline $6-8 \mathrm{hrs}$ & 24 & 9 & 33 & 2.67 & 0.36 \\
\hline Next Day & 2 & 19 & 21 & 0.11 & 0.01 \\
\hline Total & 48 & 31 & 79 & & \\
\hline \multicolumn{6}{|c|}{ Mantel-Haenszel Summary Odds Ratios and Crude OR for Each Exposure Level } \\
\hline \multicolumn{2}{|c|}{ Level 2 vs. Level 0: } & & 0.05 & 0.048 & \\
\hline
\end{tabular}




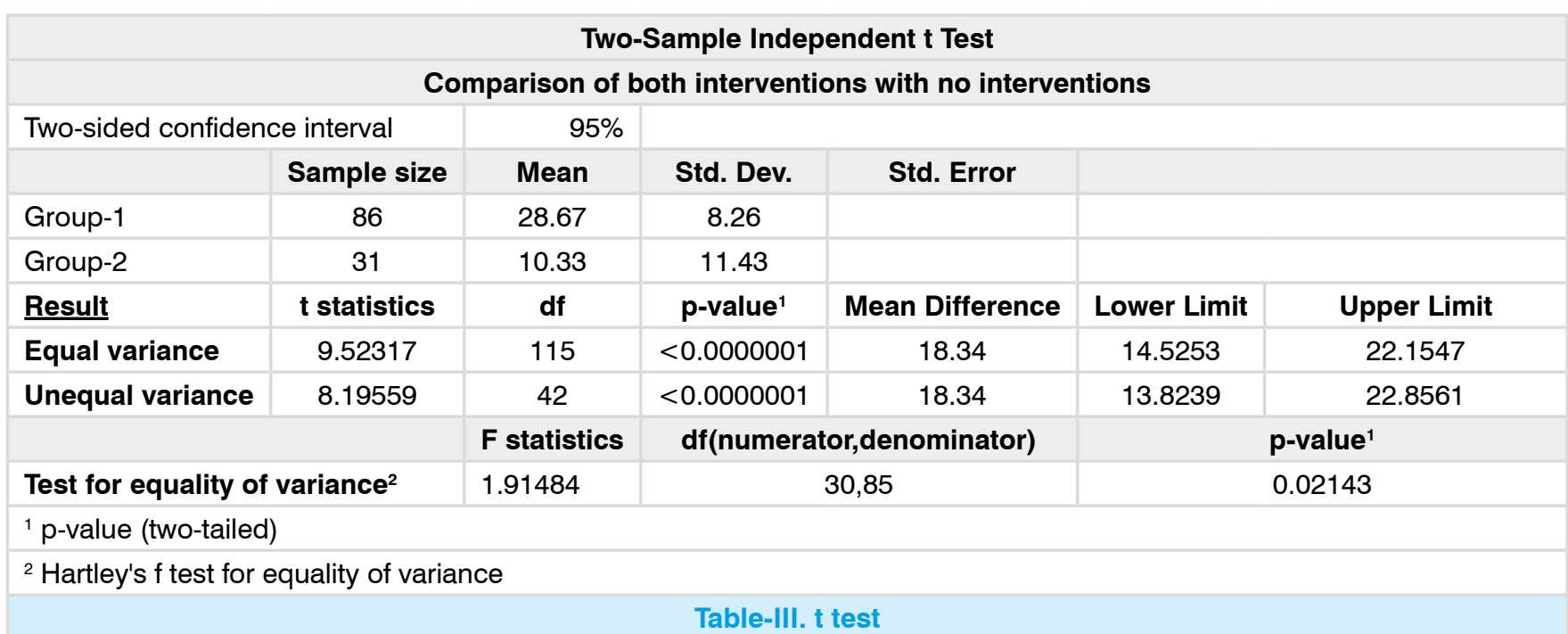

Out of these 19, 2 articles were published before 2000 (in 1997 and 1998 respectively) and thus had to be removed from the search. 3 of the articles could not be accessed as they were not free-toview (i.e. required purchasing). 4 articles were literature reviews and were excluded because they did not have a meta-analysis of RCTs conducted on the topic, and their research objectives did not meet this study. Therefore, 11 articles fitted the selection criteria of the systematic literature review, out of which there was 1 Retrospective Cross Sectional Study, 2 Case Control Studies, and 8 Randomized Control Trials. , $, 2,4-12^{2}$

\section{DISCUSSION}

Its efficacy can be increased if there are two analgesics acting together during arthroscopy, as has been shown in literature..$^{9,10}$ There was limited incidence of adverse effects from postoperation arthroscopic surgery, with only two articles describing vomiting and nausea in patients. ${ }^{4,6}$ Reasons given for the incidence of adverse effects in these articles had diagnosed a lack of drug adherence amongst the patients. In both articles, there were only two patients who had to be discharged and not considered in the studies ${ }^{4,6}$ Amongst patients who participated in this study, none had shown adverse effects postoperation.

While the type of arthroscopic method was not a part of the research objective of this study, administration of analgesic during arthroscopic surgery has shown variation between type of administration (4) and region in which it is administered. . $^{613}$ Regardless of which article is taken into consideration, gender is not a significant indicator of efficacy during postop pain management, ${ }^{1,2,4-12}$ and this finding is also provided in our study.

The findings from our study conform to the findings in literature, especially when taking into consideration post-operational pain thresholds amongst patients. The study is unique because there were few studies on post-operational pain thresholds in arthroscopic surgery, ${ }^{10,11}$ and research on the topic concerning combination analgesics in arthroscopic surgery is still ongoing.

Some limitations which were faced in this study were as follows: because of morphine restrictions, a derivative (Nalbuphin) was used, hence there was not efficacious and optimum analgesic activity; recall bias of patients as a result of use of visual analogue scale because of belief that arthroscopic treatment of knee joint is a major surgical procedure, hence they perceive more pain.

Some limitations of the systematic literature review were as follows: availability of free-toread articles; number of search engines used for this study; limited studies of patients from the South Asia region (only one article was found for India in the systematic literature review); and 
articles concerning patients aged 10 to 20 were underrepresented.

Further research on the topic concerning postoperational pain management after arthroscopic surgery may help in alleviating and improving standards whereby patients have faster recovery and mobilization post-surgery.

\section{CONCLUSION}

If this procedure is performed with the correct expertise and the patient given intra articular lignocaine and Nalbuphin, the patients show early and good recovery and therefore they can be discharged the same day thus reducing the cost on the patient as well as the hospital. No adverse effects were reported with the use of lignocaine and Nalbuphin. Thus it is recommended that following arthroscopy Intraarticular use of lignocaine and Nalbuphin is definitely beneficial for the patients.

Copyright(C) 15 Nov, 2016.

\section{REFERENCES}

1. Alagol A, Calpur OU, Usar PS, Turan N, Pamukcu Z. Intraarticular analgesia after arthroscopic knee surgery: comparison of neostigmine, clonidine, tenoxicam, morphine and bupivacaine. Knee Surg Sports Traumatol Arthrosc. 2005 May 24;13(8):658-63.

2. Al-Otaibi M. Outcomes of knee arthroscopy under local anaesthesia. J Taibah Univ Med Sci. 2013 Aug;8(2):112-4.

3. Shen H, Xia Y, Li P, Wang J, Han H. Arthroscopic operations in knee joint with early-stage tuberculosis. Arch Orthop Trauma Surg. 2009 Apr 23;130(3):357-61.

4. Alagöl A, Çalpur OU, Kaya G, Pamukçu Z, Turan FN. The use of intraarticular tramadol for postoperative analgesia after arthroscopic knee surgery: a comparison of different intraarticular and intravenous doses. Knee Surg Sports Traumatol Arthrosc. 2003 Dec 23;12(3):184-8.

5. Ekman EF, Wahba M, Ancona F. Analgesic Efficacy of Perioperative Celecoxib in Ambulatory Arthroscopic
Knee Surgery: A Double-Blind, Placebo-Controlled Study. Arthrosc J Arthrosc Relat Surg. 2006 Jun;22(6):635-42.

6. Essving P, Axelsson K, Åberg E, Spännar H, Gupta A, Lundin A. Local Infiltration Analgesia Versus Intrathecal Morphine for Postoperative Pain Management After Total Knee Arthroplasty: A Randomized Controlled Trial. Anesth Analg. 2011 Oct;113(4):926-33.

7. Hunt KJ, Bourne MH, Mariani EM. Single-Injection Femoral and Sciatic Nerve Blocks for Pain Control After Total Knee Arthroplasty. J Arthroplasty. 2009 Jun;24(4):533-8.

8. Jacobson E, Forssblad M, Rosenberg J, Westman L, Weidenhielm L. Can Local Anesthesia Be Recommended for Routine Use in Elective Knee Arthroscopy? A Comparison Between Local, Spinal, and General Anesthesia. Arthrosc J Arthrosc Relat Surg. 2000 Mar;16(2):183-90.

9. Mayr HO, Entholzner E, Hube R, Hein W, Weig TG. Pre- versus postoperative intraarticular application of local anesthetics and opioids versus femoral nerve block in anterior cruciate ligament repair. Arch Orthop Trauma Surg. 2006 May 23;127(4):241-4.

10. $\mathrm{Ng} \mathrm{H}-\mathrm{P}$, Nordström U, Axelsson K, Perniola AD, Gustav E, Ryttberg L, etal. Efficacy of Intra-Articular Bupivacaine, Ropivacaine, or a Combination of Ropivacaine, Morphine, and Ketorolac on Postoperative Pain Relief After Ambulatory Arthroscopic Knee Surgery: A Randomized Double-Blind Study. Reg Anesth Pain Med. 2006 Jan;31(1):26-33.

11. Talu GK, Özyalçın S, Koltka K, Ertürk E, Akıncı Ö, Aşık $M$, et al. Comparison of efficacy of intraarticular application of tenoxicam, bupivacaine and tenoxicam: bupivacaine combination in arthroscopic knee surgery. Knee Surg Sports Traumatol Arthrosc. 2008;10(6):355-60.

12. Usichenko TI, Hermsen M, Witstruck T, Hofer A, Pavlovic D, Lehmann C, et al. Auricular Acupuncture for Pain Relief after Ambulatory Knee Arthroscopy\&\#8212;A Pilot Study. Evid Based Complement Alternat Med. 2005;2(2):185-9.

13. Horlocker T. Anesthesia for outpatient knee arthroscopy: Is there an optimal technique? Reg Anesth Pain Med. 2003 Jan;28(1):58-63.

\section{AUTHORSHIP AND CONTRIBUTION DECLARATION}

\begin{tabular}{c|l|l|c|}
\hline Sr. \# & \multicolumn{1}{|c|}{ Author-s Full Name } & Contribution to the paper & Author=s Signature \\
\hline 1 & Dr. Moghees Ikram Ameen & Full & कrofly \\
\hline
\end{tabular}

